\title{
Facetas estéticas de porcelanas na odontologia: Uma revisão de literatura
}

\author{
Porcelain aesthetic facets in Dentistry: A literature review
}

\section{Características estáticas de porcelana em Odontologia: Una revisión de la literatura}

José Milton de Aquino e Silva Neto ${ }^{1 *}$, Anna Lígia Lima da Rocha1, Katiana Silva de Almeida Santa Cruz ${ }^{1}$, Isabel Karine Ferreira Duarte ${ }^{1}$, Michelle Leão Bittencourt Brandão Medeiros ${ }^{1}$.

\section{RESUMO}

Objetivo: A busca por um sorriso com melhor estética vem ocorrendo com uma maior frequência em nossa sociedade. Nos últimos anos a odontologia reabilitadora tem desenvolvido procedimentos que visam proporcionar ao público alvo não só a harmonia estética como também reestabelecer suas funções orais de uma forma geral, englobado tudo em um só procedimento, e desta forma expressando uma interferência direta na autoestima do paciente. Métodos: tratou-se de uma revisão de literatura, com abordagem descritiva e de caráter informativo, onde o processo de formulação se deu através de buscas por literaturas cientificas, em bases de dados, tendo como descritores: o uso de facetas em porcelana. Resultados: É uma ferramenta que vem sendo implantada de forma correta, uma vez que fundada nos princípios dos três pilares: dentista, técnica e paciente, busca restabelecer a cor do dente, função e a forma da anatomia dental, além de possuir uma ótima biocompatibilidade com os tecidos dentários envolvidos no processo de fixação. Considerações Finais: Este procedimento é considerado de fácil execução, contudo, devem respeitar as indicações e as contraindicações, seguindo um correto protocolo clinico no intuito da obtenção de um resultado satisfatório e duradouro.

Palavras-chave: Estética dentária, Porcelana dentária, facetas dentárias, reabilitação bucal.

\begin{abstract}
Objective: The search for a smile with a better aesthetic has occurred with a higher frequency in our society. In recent years rehabilitation dentistry has developed procedures where it seeks to provide target audience with not only the aesthetic part but also their functions in a general way. encompassed in a single procedure, exposing a direct interference in the patient's self-esteem. Methods: This was a literature review, with a descriptive approach with an informative character, where the formulation process was carried out through searches by scientific literature, in databases, having as descriptors the use of ceramic laminated Porcelain. Results: this technique has been correctly implanted, because it seeks to restore the color of the tooth in a conservative way, restoring the shape of the dental anatomy, besides having an excellent biocompatibility with the tissues involved in the fixation of the tooth to the bone. Final Considerations: This procedure is considered easy to perform, however, should comply with indications, contraindications and clinical protocol in order to obtain a satisfactory result.
\end{abstract}

Key Words: Esthetics dental, Dental Porcelain, dental Veneers, Mouth Rehabilitation.

\section{RESUMEN}

Objetivo: La búsqueda de una sonrisa com una estética mejor há ocorrido con la mayor frecuencia en nuestra sociedade, em los últimos años la Odontología reabilitadora se há desplazado em busca de un problema de salud. Englobado en un solo procedimento, exponiendo uma interferência directa em la autoestima del paciente. Métodos:Se trató de uma revisión de literatura, com abordaje descriptivo com base em datos, teniendo como base de datos de búsquedas por literaturas científicas, em base de datos, teniendo como descriptores: el uso de faceta laminada em porcelana. Resultados: La técnica viene siendo implantada de

${ }^{1}$ Centro Universitário CESMAC (CESMAC), Maceió-Alagoas. *E-mail: Milton neto 166@hotmail.com 
forma correcta pues busca restabelecer el color del diente de uma forma conservadora, restableciendo la forma de la anatomia dental, además de poseer uma óptica biocompatibilidad com los tejidos implicados em la fijación del diente al hueso. Consideraciones finales: Este procedimento se considera de fácil aplicación, sin embargo, deben restar las indicaciones, las contraindicaciones y el protocolo clínico com el fin de obtener un resultado satisfactorio.

Palabras Clave: Estética Dental, Porcelana Dental, Coronas con Frente Estético, Rehabilitación bucal.

\section{INTRODUÇÃO}

O uso da porcelana na odontologia foi sugerido em 1728 pelo médico francês Pierre Fouchard, considerado o pai da odontologia moderna, quando já em 1774, Alixis Duchate, um boticário também francês, observou que as próteses dentárias à base de porcelana possuíam maior resistência ao manchamento bem como durabilidade quando comparadas as próteses dentais de marfim, introduzindo por vez a porcelana odontológica ou cerâmica dental. (AMOROSO AP, et al., 2012).

A ideia de confeccionar facetas de porcelana ou laminados cerâmicos surge no início do século XX ao observar a necessidade dos astros de cinema em possuir e exibir dentes harmoniosos e estéticos. Na época o dr.Charles Pincus, cirurgião-dentista, que era respeitado pelo meio artístico e instrutivo de Beverly Hills, foi então contratado para obter resultados que melhorasse tais problemas, o mesmo conseguiu efeitos satisfatórios, criando um método que reestabelecia a estrutura dental que estava comprometida utilizando lâminas de porcelana (BISPO LP, 2009).

Nos últimos tempos a compreensão de estética oral vem se demonstrado bastante diversificada, variando por região, relacionada a valores sócio econômico-culturais, a fatores psicológicos, modificando-se constantemente de acordo com a época e o país. Porém apesar de ser um critério bastante subjetivo a objetividade do tratamento está em ser realizado obedecendo preceitos da anatomia dental, simetria e proporção, com maior preservação da estrutura sadia, bem como da relação existente entre os dentes vizinhos e seus antagonistas, como posição e alinhamento, buscando além da estética a reabilitação funcional, tudo baseado num correto diagnóstico e planejamento (PERGORARO L F, 2013).

Hoje o uso das facetas em porcelana é um dos recursos mais avançados no que se refere a harmonização orofacial. Muitos profissionais consideram-na um dos grandes progressos científicos do século na área da odontologia estética, sendo um dos procedimentos mais buscados por pessoas cujo o trabalho esteja voltado à aparência, além de estar interligado e correlacionado com a elevada autoestima e bem-estar do paciente (KELLY J R e BENETTI P, 2011).

O padrão de otimização das facetas em cerâmica e seu atual status só foi obtido devido a busca pela excelência nas qualidades ópticas e físicas das cerâmicas aliada ao aumento no conhecimento das técnicas adesivas desenvolvidas nos últimos anos (JÚNIO B e BARROS C, 2011).

Os procedimentos feitos com as facetas de porcelana não exigem muita tecnologia ou materiais inovadores, mas sim a junção de dois requisitos tradicionais, que é a porcelana, com espessura suficientemente homogênea, e o cimento resinoso, ambos capazes de restaurar a rigidez coronária (MAGNE P e BELSER U, 2003).

Com o desenvolvimento das técnicas adesivas e o aprimoramento dos materiais, as facetas indiretas vêm sendo utilizadas como alternativas restauradoras que buscam, hoje em dia, comprometer minimamente o desgaste do dente durante a fase do preparo dentário, estabelecendo em tempo hábil a harmonia no sorriso do paciente (JÚNIO B e BARROS C, 2011).

Por ser um tema bastante abrangente, o presente trabalho possui como objetivo estabelecer os principais aspectos que estão relacionados as facetas de porcelana: indicações e contraindicações, vantagens e desvantagens, bem como seu protocolo de confecção e cimentação, indo desde a escolha dos materiais utilizados até sua adesão no meio bucal. 


\section{METODOLOGIA}

Esta pesquisa constituiu-se através de uma revisão de literatura realizada entre os períodos de Março de 2019 a julho de 2019, onde foram analisados artigos publicados em bases de dados eletrônicos LILACS (Literatura Latino Americana e do Caribe em Ciências da Saúde), MEDLINE (Literatura Internacional em Ciência da Saúde) e SCIELO (Scientific Electronic Library Online) e livros que estavam disponíveis nos acervos bibliográficos presentes na biblioteca central do Centro Universitário CESMAC (Centro de Ensino Superior de Maceió).

Foram consultados textos em língua portuguesa e inglesa, que se referiram as facetas de porcelanas na Odontologia, tendo como critérios de exclusão os períodos de publicações e os artigos que não possuíam relevância com a temática, sendo selecionados os textos científicos que apresentavam na integração real objetivo do trabalho, observando a evolução da aplicação das facetas até os dias atuais. Os descritores utilizados foram: Facetas estéticas no uso odontológico, desgaste dentário e harmonização do sorriso.

\section{RESULTADOS E DISCUSSÃO}

A evolução dos matérias e o avanço técnico-científico da odontologia restauradora adesiva proporcionou mudanças dos paradigmas preexistentes na sociedade, transformando-a de uma odontologia que causava trauma e temor para uma odontologia que concebe beleza e bem-estar (SOARES et al, 2012). Nas últimas décadas o valor estético-bucal tem se elevado e a população de uma maneira geral, possuindo um alto grau de exigência, vem buscando sempre chegar no que julga ser a perfeição. No campo odontológico atualmente, a procura corriqueira dos pacientes por tratamento não só com fins reparadores, mas para fins estéticos do meio bucal, vem aumentando, tornando-se motivação para os pesquisadores pela busca de novas técnicas e otimização das já existentes (SILVA W e CHIMELI T, 2011).

O panorama sobre restaurações de dentes cariados na odontologia foi modificado para intervenção estética em dentes sadios. Com o objetivo de se adequar e seguir padrões de beleza numerosamente exposto nas redes sociais e meios de comunicações, bem como possuindo um alto grau de exigência estética, os pacientes estão procurando possuir sorrisos perfeitos e igualmente formatados (OKIDA RC, et al., 2016). Contudo Menezes MS, et al. (2015), ressalta que para qualquer tipo de reabilitação restauradora o cirurgiãodentista deve optar por meios mais conservadores, com o objetivo de evitar desgastes desnecessários da anatomia dental.

O uso odontológico das porcelanas vem ao longo do tempo sendo uma das melhores alternativas no que se refere ao tratamento para a resolução de problemas estruturais dos dentes. Vários fatores contribuem para a sua utilização, principalmente por serem quimicamente e mecanicamente compatíveis, além de possuírem baixa condutividade térmica e elétrica, bem como resistência a compressões e excelente estrutura para poder simular os dentes naturais (NASCIMENTO AS, et al., 2015).

Estudos clínicos comprovam várias vantagens no uso das facetas de cerâmicas, tais como ser um material biocompatível, possuir grande resistência adesiva, além de apresentar uma superfície lisa que permite a recuperação e uma boa manutenção da saúde periodontal através da diminuição do acúmulo de placa bacteriana, bem como apresentar alta resistência ao meio bucal e grande semelhança com a cor dos dentes naturais (BISPO L B, 2009).

Foi realizado um estudo com facetas e através dele foi observado que $93 \%$ das 3500 facetas em porcelana no período de 15 anos tiveram resultados positivos e que $7 \%$ não obtiveram um resultado satisfatório. Com isso pode ser constatado que as falhas nas memórias estavam associadas a fraturas, a micro infiltração e a perda da adesão. No que se refere as falhas a maioria, cerca de $67 \%$, estava diretamente relacionada às fraturas. Assim, pode ser averiguado que a maioria das fraturas ocorreram no bordo incisal das facetas por causa dos meios de tensões exercidas, justificando para tanto que a adesão invasiva (ataque ácido) era mais forte que a adesão química (silano) (FRIEDMAN MJA, 1998). 
Strassler HE (1989), obteve grande sucesso (93\%) das facetas de porcelana depois de 7 a 10 anos. Um sucesso mais baixo foi reportado por Dunne SM e Millar BJ (1993), onde foi observado que $17 \%$ das restaurações precisavam de reparos ou substituições após 5 anos. Nele foi analisado que a responsabilidade por esse insucesso se deu devido ao uso de agentes de cimentação não apropriados.

O desenvolvimento e a evolução das técnicas de condicionamento ácido do esmalte e de dentina, como também dos sistemas adesivos fez com que a resistência da união entre o laminado de porcelana e o dente torne-se extremamente forte, uma vez que a relação entre os dois aumentava a força de união entre o dente e a faceta, associando com isso a utilização dessa técnica de maneira definitiva. (CONCEIÇÃO EN, 2009).

Foi avaliado durante 5 anos 186 facetas laminadas em 61 pacientes, onde 98,4\% das facetas foram consideradas com ótimas características adesivas, físicas e químicas, sendo aceitas clinicamente. Suas retenções estavam em perfeitas condições, e no que se refere a manutenção da estética estavam em perfeito estado (ARISTIDIS GA, 2002).

Peumans M, et al. (2000), avaliou que depois de 5 anos, $93 \%$ das facetas em porcelana permaneceram satisfatórias e não precisaram de intervenção. Enquanto 7\% dos pacientes estavam com deficiências inaceitáveis clinicamente $(2.3 \%$ foram devido a cáries recorrentes, $1,2 \%$ por consequência de fratura da porcelana, 1,2\% micro infiltração marginal, 2,3\% por reação pulpar) no que poderia ser feita uma restauração para correção. Com isso o estudo indicou que as facetas são restaurações duradouras. Isso devido os resultados que obtiveram, onde só 6 das 87 restaurações estavam sendo inaceitáveis e precisaram de alguns reparos.

Dumlfahrt FT e Schaffer R (2000), estudaram e observaram clinicamente 205 facetas laminadas de porcelana por 10 anos e constataram ótimos resultados, tendo visto que a porcentagem de longevidade das facetas foi de $97 \%$ em 5 anos e de $91 \%$ em 10 anos. Para tanto foram colocados em consideração: o tempo de uso e os cuidados dos pacientes, gerando uma grande influência na qualidade das porcelanas.

As manutenções das margens do preparo devem ficar restritas ao esmalte, evitando e impedindo a ocorrência de microinfiltrações e suas consequências, tais como manchamento marginal e recessão gengival. (LACY AM, 2002). Já Baratieri LN, et al. (2008) afirma que nos preparos para laminados cerâmicos seus contatos proximais devem ser conservados em dente natural, pois facilita $\mathrm{o}$ ajuste e encaixe da faceta $\mathrm{e}$ promove um melhor controle do biofilme dental.

A resistência do material cerâmico também deve ser analisada pelo profissional reabilitador. Para tanto subdividiu as cerâmicas de acordo com o grau de resistência flexural em mega-pasal (MPa): baixa resistência (100 a $150 \mathrm{Mpa}$ ) onde se enquadram cerâmicas de feldspato e leucita; resistência moderada (300 a $900 \mathrm{MPa}$ ) onde estão as cerâmicas reforçadas por dissilicato de lítio, silicato e alumina; e a alta resistência (1000 a 1200 Mpa) cujas as cerâmicas são as que contém alto teor de zircônia (MARTINEZ FR, et al., 2007)

As facetas de porcelana apresentam dois grandes problemas: o desgaste no dente antagonista e a formação de trincas e fraturas. Apesar das cerâmicas apresentarem elevada resistência a compressão, elas possuem baixa resistência a tração, as facetas que não recobrem a borda incisal correspondem a $13 \%$ de risco de fratura da porcelana na borda incisal, sendo de extrema necessidade a redução dessa borda entre 1 a $1,5 \mathrm{~mm}$ de espessura (SCHMIDSEDER J e MARDI M, 2002).

A presença de bruxismo e hábitos parafuncionais está diretamente relacionada ao surgimento de trincas nas restaurações e comprometimento na longevidade das porcelanas, sendo uma excelente opção para o tratamento o uso de placas oclusais. A utilização clínica de facetas reforçadas por dissilicato de lítio, uma vez que as mesmas apresentam, além de uma boa qualidade estética e melhor adesão, uma elevada resistência flexural, causando um menor desgaste do dente antagonista (GRANELL-RUIZ M, et al., 2014)

A restauração em porcelana embora seja uma excelente opção de tratamento, deve se reconhecer que sua longevidade depende das propriedades químicas e mecânicas dos materiais escolhidos ( porcelana , sistema adesivo e cimento), das cargas mastigatórias que as facetas são submetidas, da associação da cerâmica ao substrato dentário (falha de cimentação em $80 \%$ de preparos em dentina) como também a 
proporção da espessura do cimento resinoso e cerâmica(quanto menor espessura de cerâmica e maior de cimento, maior será a propensão de surgir fendas), tendo grande influência na distribuição das tensões nas restaurações (SOUZA EM, et al., 2002).

Quanto à cor final da restauração em cerâmica, contempla uma etapa importante do tratamento. A escolha adequada da espessura da porcelana representa um passo crítico no procedimento. Sua espessura é determinada pela coloração do substrato dentário, assim, quanto mais pigmentado o substrato, maior será o desgaste e a espessura da faceta (ANDRADE RT, et al., 2012).

A coloração dentaria é alterada com a utilização de peróxido de carbamida a $10 \%$. As modificações que são observadas melhoram a coloração das facetas obtendo assim um contentamento do paciente e do profissional que realizou o procedimento, e anular a indispensabilidade da disposição de facetas mais consistentes para a retificação da cor, por isso a importância de sempre ter um diálogo direto com o paciente (ANDRADE RT, et al., 2012).

De acordo com os respectivos relatos foi ressaltado por esses autores que os dentistas devem fazer uma correta escolha, seja ela de um possível clareamento e/ou colocar as facetas, mesmo sabendo que o clareamento não muda a cor das facetas de porcelana, observa-se que o clareamento dos elementos dentais que são revestidos por porcelana pode modificar a estética da cor das facetas em porcelana, porém não obtendo um resultado esperado e desejado pelo paciente ( ANDRADE RT, et al., 2012).

A escolha da cor dos cimentos resinosos utilizados na adesão pode influir na cor final da faceta, sugerindo a aplicação de um cuidadoso protocolo clínico, sendo criterioso desde a seleção e análise do caso até à cimentação final definitiva. Ele relata que quanto mais leve é o manchamento do substrato dentário, mais suave é o desgaste do preparo, porém quanto mais forte é o manchamento, mais agressivo é o desgaste e mais espessa é a faceta de porcelana (LISBOA TN e SOUZA FB., 2016).

Quanto à relevância periodontal, a importância do ajuste e acabamento das margens gengivais do preparo, como a mínima extensão dentro do sulco, podendo variar de 0 a $1 \mathrm{~mm}$ de profundidade, bem como encontrarse supra gengival nos casos em que o paciente não expõe gengiva durante o sorriso, evitando assim periodontites pelo acúmulo de bactérias no sulco gengival (PROFFIT W, 2011).

Para uma excelência do tratamento, é de suma importância a precisão extrema do cirurgiã-dentista tanto no preparo intra-oral, quanto na produção laboratorial da faceta, como também a participação e colaboração do paciente no que diz respeito a sua opinião versus indicação; a sua conduta durante o tratamento; a manutenção da saúde bucal; hábitos parafuncionais prejudiciais que comprometam o êxito e a observação periódica associada a durabilidade do procedimento (PROFFIT W, 2011).

O sucesso das facetas em cerâmica se deve a minuciosa atenção aos detalhes, indo desde um bom planejamento do caso, através de um estudo funcional e estático do paciente por meio de uma criteriosa análise de fotos, radiografias, exames físicos e completa anamnese, passando por um correto diagnóstico, seleção do sistema cerâmico e dos materiais e métodos de cimentação até a cuidadosa e conservadora confecção do preparo, cimentação, acabamento e polimento da restauração e contínua manutenção pós tratamento (CALAMIA JR e CALAMIA CS, 2007)

Quando é ressaltado sobre facetas na literaturas, suas indicações devem ser precedidas por uma criteriosa análise dos casos e a constatação da real necessidade deste tratamento, pois o bom senso é fundamental, já que a conservação das estruturas dentárias é um dos principais objetivos da odontologia contemporânea, como pode ser analisado na Quadro 1 (OKIDA RC, et al., 2016).

Seguindo esse raciocínio são classificadas as porcelanas de acordo com sua composição em dois grandes grupos: Vitreas, que são as porcelanas à base de feldspáticas; à base de leucita; de dissilicato de lítio; de silicato de lítio com $10 \%$ de zircônia; e as não vítreas, reforçadas por óxidos à base de alumina ou à base de zircônia (KELLY JR e BENNITI P, 2011). 
Quadro 1 - Indicações e contraindicações, bem como vantagens e desvantagens para o sucesso desta reabilitação.

\begin{tabular}{|c|c|c|c|}
\hline INDICAÇÕES & CONTRAINDICAÇÕES & TAGENS & IS \\
\hline 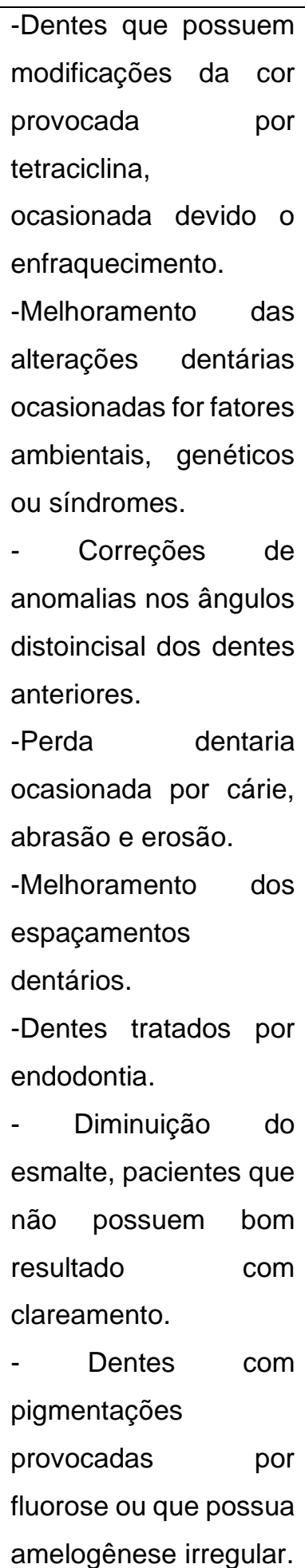 & $\begin{array}{l}\text { - Quando o caso requer o } \\
\text { desgaste de mais de } 50 \% \\
\text { do esmalte. } \\
\text {-Quando os ângulos da } \\
\text { faceta não ficam por } \\
\text { inteiro situados no } \\
\text { esmalte dental. } \\
\text {-Pacientes que são } \\
\text { portadores de costumes } \\
\text { parafuncionais. } \\
\text { - Pacientes com grande } \\
\text { recorrência de cárie ou } \\
\text { retração gengival. } \\
\text {-Dentes que apresentam } \\
\text { grande extensão de } \\
\text { restauração. } \\
\text {-Maloclusão } \\
\text { devido a sobrtical } \\
\text { dos dentes anteriores e } \\
\text { superiores. } \\
\text {-Dentes exageradamente } \\
\text { vestibularizados. } \\
\text {-Dentes que não possuem } \\
\text { retenções em suas coroas } \\
\text { clínicas. } \\
\text {-Paciente que não se } \\
\text { preocupam com a } \\
\text { higienização oral. }\end{array}$ & 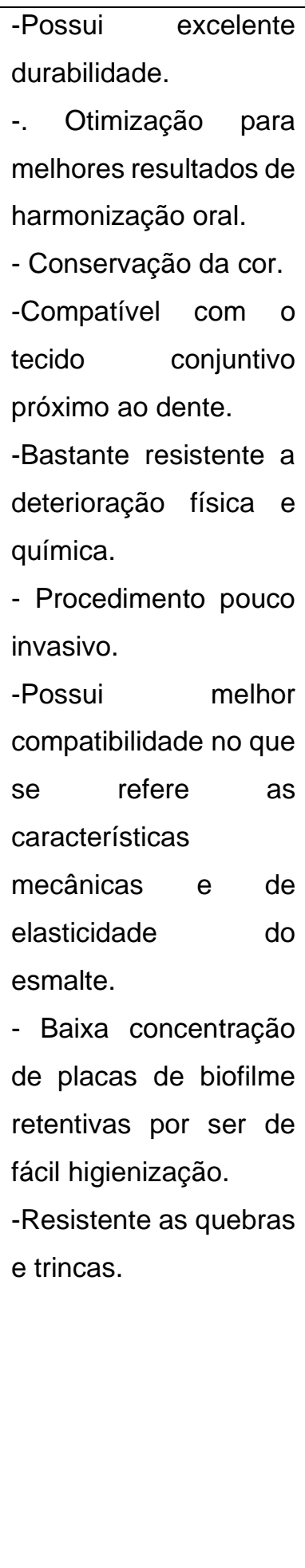 & $\begin{array}{l}\text { - Requer tempo para } \\
\text { confecção } \\
\text { porcelanas. } \\
\text { - Obtenção de ótimo } \\
\text { resultado é necessário } \\
\text { muito aperfeiçoamento do } \\
\text { profissional. } \\
\text {-Procedimentos para } \\
\text { aplicação são bastante } \\
\text { cautelosos para a fixação } \\
\text { com ótima longevidade. } \\
\text {-São muito sensíveis } \\
\text { quando não estão fixadas } \\
\text { aos elementos dentários, } \\
\text { podendo ocorrer casos } \\
\text { indesejados de fraturas. } \\
\text {-Não é indicado fazer } \\
\text { reparos se porventura } \\
\text { ocorrer trincas. } \\
\text { - Os provisórios são } \\
\text { difíceis de serem feitos e } \\
\text { requer paciência } \\
\text { habilidade do profissional. }\end{array}$ \\
\hline
\end{tabular}

Fonte: (OKIDA RC, et al., 2016); (LISBOA TN e SOUZA FB., 2016).

Considerando que as cerâmicas não vítreas, por não possuírem união adesiva, ou seja, por serem ácido resistente, em casos, por exemplo, que necessitam de facetas com excelentes propriedades ópticas e baixa espessura para adesão, como as facetas laminadas minimamente invasivas, as cerâmicas vítreas por 
possuírem alto teor de sílica, representam a melhor opção de escolha em detrimento das não vítreas (SOARES PV, et al., 2012).

O conhecimento das características das porcelanas é de fundamental importância dentro do desempenho clínico, assim como os procedimentos básicos devem ser criteriosamente estudados para uma excelente execução do tratamento e a obtenção de um melhor resultado quanto a resistência de união e longevidade da restauração (SOARES PV, et al., 2012). Como é demostrado na Quadro 2.

Quadro 2 - Etapas da implantação da faceta.

\begin{tabular}{|l|l|}
\hline \multicolumn{1}{|c|}{ Etapas } & \multicolumn{1}{c|}{ Execução } \\
\hline $\begin{array}{l}\text { 1 - Preparo dentário } \\
\text { convencional. }\end{array}$ & $\begin{array}{l}\text { Obedecendo os princípios de extensão, retenção, estabilidade e } \\
\text { rigidez; }\end{array}$ \\
\hline $\begin{array}{l}2 \text { - Moldagem e confecção do } \\
\text { provisório. }\end{array}$ & $\begin{array}{l}\text { U Uso do fio afastador para visualização dos terminos cervicais } \\
\text { epermitindo um perfil de emergência mais adequado e confecção do } \\
\text { mock up preenchido com resina bisacrílica no preparo; }\end{array}$ \\
\hline $\begin{array}{l}3 \text { - Condicionamento ácido- } \\
\text { cerâmico. }\end{array}$ & $\begin{array}{l}\text { Execução da limpeza (ácido fosfórico 37\%) e condicionamento ácido } \\
\text { (ácido hidrofluorídrico 10\%) da superfície interna dos laminados; }\end{array}$ \\
\hline 4 - Silanização da cerâmica. & União do silano ao dióxido de silício presente nas cerâmicas vítreas; \\
\hline 5- Isolamento Absoluto. & $\begin{array}{l}\text { Utilização de dique de borracha, personalização dos grampos, } \\
\text { amarrias e arco total ou parcial; }\end{array}$ \\
\hline 6- Sistema adesivo dentinário. & $\begin{array}{l}\text { Condicionamento ácido (ácido fosfórico 37\%) seguido de lavagem, } \\
\text { secagem e aplicação do sistema adesivo; }\end{array}$ \\
\hline 7 - Cimentação. & $\begin{array}{l}\text { específico para cada caso, sendo o mais utilizado o cimento } \\
\text { fotopolimerizável por apresentar variedades de cor e opacidade como } \\
\text { também um bom escoamento e maior estabilidade de cor. }\end{array}$ \\
\hline
\end{tabular}

Fonte: Modificada de (SOARES PV, et al., 2012); (LISBOA TN e SOUZA FB., 2016).

\section{CONSIDERAÇÕES FINAIS}

Com a grande evolução e desenvolvimento das técnicas cerâmicas e o aprimoramento respectivos dos materiais, que buscam obter uma melhor resistência à flexão e tração, maior semelhança com os dentes naturais, as facetas estão sendo utilizadas como alternativas restauradoras que visam, hoje em dia, o comprometimento mínimo do desgaste dental durante a fase do preparo dentário, estabelecendo em tempo hábil a harmonia no sorriso do paciente. Por isso é de suma importância que cada vez mais o Cirurgião Dentista se qualifique e obtenha um melhor conhecimento cientifico dos mais variados produtos que estão acessíveis no mercado, bem como conhecer suas indicações, contraindicações e fatores limitantes, com o objetivo de estabelecer uma restauração harmoniosa e que preserve toda anatomia dental para poder alcançar maior existência de vida clínica.

\section{REFERÊNCIAS}

1. AMOROSO AP, et al. Cerâmicas odontológicas: Propriedades, indicações e considerações clínicas. Revista Odontológica de Araçatuba, v.33, n.2, 2012; p.19-25

2. ANDRADE RT, et al. Ultimate ceramic veneer: A laboratory-guided reparation technique for minimally invasive laminate veneers Journal of the California Dental Association 2012; 40(6) 489-494

3. ARISTIDIS GA. Five-year performance of porcelain laminate veneers. Quintessence Internacional. v.33, n.3, 2002 p.185-188.

4. BARATIERI L N, GUIMARÃES J. Laminados cerâmicos. In: BARATIERI, L. N.; MONTEIRO, S. M.; et al. Soluções clínicas: fundamentos e técnicas. Santa Catarina. 2008, P314-375

5. BISPO LB. Facetas Estéticas: Status da Arte. Revista Dentística On Line, Santa Maria, a.8, 2009; n.18, p.11-14.

6. CALAMIA JR, CALAMIA CS. Porcelain laminate veneers:reasons for 25 years of success. Dent Clin North Am, v.51, 2007; p.399-417

7. CASTELNUOVO J. et al. Fracture load and mode of failure of ceramic veneers with different preparations. J. Prosthet Dent, v.83, 2000; p. 171-180 
8. CONCEIÇÃO EN. Restaurações Estéticas: Compósitos, Cerâmicas e Implantes. Artmed Editora, 2009

9. DUMFARHRT FT, SCHAFFER, H. Porcelain laminate veneers. A restropctive evaluation after 1 to 10 years of service: Part II clinical result. Int J Prosthodont, v.13, 2000; p.09-17

10. DUNNE SM, MILLAR B J. A longitudinal study of the clinical performance of porcelain veneers. Br. Dent. J. v,175, n.9, 1993; p.317-321

11. GRANELL-RUíZ M, et al. Influence of bruxism on survival of porcelain laminate veneers. Medicina Oral, Patología Oral y Cirugía Bucal. v.19, n.5, 2014; p.426- 432

12. JÚNIOR B, BARROS C. (2011). Reabilitação Estética com Faceta Indireta em Porcelana, Revista Odontológica do Planalto Central, 2 (1), 2011; pp.9-15

13. KELLY J R, BENETTI P. Ceramic materials in dentistry: historical evolution and current practive. AustDent J., v.56, n.1, 2011; p.84-96

14. LACY AM. Porcelain veneers - Problems and solutions. Dent.Today. California, v.21, n.8,2002; p.46-51.

15. LISBOA TN, SOUZA FB. Facetas Indiretas de Consultório: Uma Alternativa Socialmente Viável. Odontologia Clínica Cientifica, Recife, v.3, n.5, 2016; p.213-217,

16. MAGNE P, BELSER U. RestauraçõesAdesivas de Porcelana na Dentição Anterior — Uma Abordagem Biomimética. São Paulo: Quintessence Ed., 2003.

17. MARTINEZ FR, et al. Cerámicas dentales: classificación y criterios de seleccion. RCOE, Madrid, v.12, n.4, 2007; p.253-263,

18. MENEZES MS, et al. Reabilitação estética do sorriso com laminados cerâmicos: Relato de caso clínico. Revista Odontológica Brasil Central, Brasil, v.24, n.68, 2015; p.37-43

19. NASCIMENTO AS, et al. Facetas: cimentação adesiva com cimento vaneer. FOL - Faculdade de Odontologia de Lins. v.25, n.2, 2015; p.67-73

20. OKIDA RC, et al. Lentes de Contato: Restaurações Minimamente Invasivas na Solução de Problemas Estéticos. Revista Odontológica de Araçatuba, Araçatuba, v.37, 2016; p.53-59

21. PERGORARO LF. Prótese fixa: Bases para o planejamento em reabilitação oral. São Paulo: Artes médicas,2013.

22. PEUMANS M, et al. Porcelain veneers: a review of the literature. J. Dent, v.28, n.3, 2000; p.163- 177

23. PROFFIT W. Soriso de Porcelana. In: PROFFIT, W. R., FIELDS, H. W. Jr., SARVER, D. M. (Org). Ortodontia Contemporânea. Rio de Janeiro: Elsevier, 2011; p. 3-21.

24. SCHMIDSEDER J, MARDI M. Facetas: do Planejamento a Manutenção. In:SCHMIDSEDER, J. Odontologia Estética. São Paulo: Artes médicas, 2002; 206p. Cap.5.

25. SILVA W, CHIMELI T. Transformando sorrisos com facetas diretas e indiretas. Revista Dentística On Line Brasil, v.10, n.21, 2011; p.41-43

26. SOARES PV, et al. Reabilitação Estética do Sorriso com Facetas Cerâmicas Reforçadas por Dissilicato de Lítio. Revista Odontológica Brasil Central, Brasil, v.21, 2012; n.58, p.538-543

27. SOUZA EM, et al. Facetas estéticas indiretas em porcelana. JBD, Curitiba, v.1, n.3, 2002; p.256-262 STRASSLER HE. Clinical evaluation of etch porcelain veneers over a period of 18 to 42 months. J Esthet Dent $1989 ; 1: 21-28$. 